\title{
Morphological Studies of Developmental Stages of Oculotrema hippopotami (Monogenea: Polystomatidae) Infecting the Eye of Hippopotamus amphibius (Mammalia: Hippopotamidae) Using SEM and EDXA with Notes on Histopathology
}

\author{
Nataliya Yu. Rubtsova ${ }^{1, *}$, Richard A. Heckmann², Willem J. Smit' ${ }^{3}$, Wilmien J. Luus-Powell ${ }^{3}$, Ali Halajian ${ }^{3}$, Francois Roux ${ }^{4}$ \\ 1'Institute of Parasitic Diseases (IPD), 11455 East Via Linda, \#2-419, Scottsdale, Arizona, 85259, USA; '2Department of Biology, 1114 WIDB, Brigham \\ Young University, Provo, Utah 84602, USA; ${ }^{3}$ Department of Biodiversity, University of Limpopo, Sovenga, 0727, South Africa; ${ }^{4}$ Mpumalanga Tourism \\ and Parks Agency, Lydenburg, Mpumalanga Province, 1120, South Africa
}

\begin{abstract}
The present study was performed to observe histopathological effects of Oculotrema hippopotami Stunkard, 1924 infection in the eye of Hippopotamus amphibius, as well as to reveal new details of morphology and structural features of this monogenean and its comparison between 2 age stages of the parasite. This was done using both light and scanning electron microscopy, energy dispersive X-ray analysis (EDXA) and histopathology. The presence of a mixture of different generations (adult and sub-adult) in one host individual is common for Oculotrema Stunkard, 1924 in contrast to Polystoma Zeder, 1800. New metrical and graphical information obtained for adults and sub-adults compared with the previous studies. Here we show the presence of genital papillae in adults, metrical data on the distal part of the vas deferens. SEM micrographs of sperm ejaculatory structures and information about the flattened dorsal side of the body provided for the first time. Histopathological changes, such as necrosis and hemorrhage in host tissues as a result of $O$. hippopotami attachment structures are described. Structural analysis of different body parts of $O$. hippopotami of both age groups are also included. We show qualitative differences in the presence of hardening ions $(\mathrm{S}, \mathrm{P}, \mathrm{Ca})$ in attachment structures (oral and haptor suckers) that increase with the age of the worm. The presence of sub-adults and adults on the same host, together with high levels of infection without high pathogenicity may account for Oculotrema being one of the most successful parasites among the Monogenea.
\end{abstract}

Key words: Oculotrema hippopotami, Hippopotamus amphibius, Polystomatidae, sub-adult, adult, histopathology, structural analysis, SEM, EDXA

\section{INTRODUCTION}

Oculotrema hippopotami Stunkard, 1924 (Oculotrematinae Yamaguti, 1968), the only monogenean known for successful colonization on a mammal poses many unanswered questions. It was originally described from Hippopotamus amphibius Linnaeus, 1758 from the Giza Zoo (Egypt), but has also been reported from Sudan and Uganda [1], Zimbabwe [2] and South Africa [3,4]. Stunkard gave a comprehensive description of $O$. hippopotami, though based on highly contracted speci-

• Received 19 May 2018, revised 16 September 2018, accepted 9 October 2018.

*Corresponding author (nyrubtsova@gmail.com)

(c) 2018, Korean Society for Parasitology and Tropical Medicine

This is an Open Access article distributed under the terms of the Creative Commons Attribution Non-Commercial License (http://creativecommons.org/licenses/by-nc/4.0) which permits unrestricted non-commercial use, distribution, and reproduction in any

medium, provided the original work is properly cited. mens [5]. Du Preez et al. [4] amended the original description of an adult by adding information on size of the parasite, particulars of egg and copulatory system structure, redefined morphological parameters of adults, and revealed the presence of a bucco-oesophageal canal, a uterine evagination, an operculated egg, the retention of marginal hooklets in the mature parasite and the ability to double its length and feed over a large area around its position of attachment. They reported a maximum of 24 parasites on a single eye and a maximum of 37 on an individual host specimen. The prevalence was found to be $75 \%$ for adults, $85 \%$ for sub-adults and $90 \%$ for the total sample [4]. In addition, Du Preez et al. and Tinsley [4,6] studied oncomiracidia and Thurston studied the larvae of O. hippopotami [7]. Sub-adults of O. hippopotami were briefly mentioned in a few publications but never were studied exclusively. Although Thurston [7,8] and Du Preez et al. [4] mentioned 
immature worms (sub-adults), but none provided more details about them.

Some studies have been devoted to the habitat of this monogenean, the hippopotamus eye tissues, but their histopathological changes at the place of attachment of the parasite have never been studied. The same applies to details of the distal parts of the copulatory system that have not been studied using scanning electron microscopy (SEM) [9]. To date there are no comparative studies on morphological and metrical characteristics of adults and sub-adults of $O$. hippopotami. In addition, this is the first study on the structural analysis of this parasite comparing adult and sub-adult forms and providing further information on this unique mammalian monogenean.

\section{MATERIALS AND METHODS}

\section{Host animals and sample collection}

A total of 6 hippopotami (Hippopotamus amphibius: 4 males and 2 females) were examined in Mpumalanga Province, South Africa in August and September 2016. The geographical coordinates for the hippopotamus examined are listed in Table 1. After collecting monogeneans, the host tissue was biopsied and fixed with 10\% buffered formalin for histopathological studies. For the morphological examination, parasites were relaxed in a small Petri-dish with $0.9 \%$ saline, and while between 2 microscope slides were fixed by $70 \%$ ethanol.

\section{Microscopical examination}

Worms were stained in Mayer's acid carmine, destained in $4 \%$ hydrochloric acid in 70\% ethanol, dehydrated in ascending concentrations of ethanol (12 hr each), and cleared in $100 \%$ xylene and then in 50\% Canada balsam and 50\% xylene (12 hr each). Whole worms were then mounted in Canada balsam.

\section{Scanning Electron Microscopy (SEM)}

Specimens fixed and stored in 70\% ethanol were processed following standard methods [11], which included critical point drying in sample baskets and mounted on SEM sample mounts (stubs) using conductive double-sided carbon tape. Samples were coated with gold and palladium for 3 min using a Polaron \#3500 sputter coater (Quorum (Q150 TES) www. quorumtech.com) establishing an approximate thickness of $20 \mathrm{~nm}$. Samples were placed and observed in an FEI Helios Dual Beam Nanolab 600 (FEI, Hillsboro, Oregon, USA) Scan- ning Electron Microscope and digital images were obtained in the Nanolab software system (GEI, Hillsboro, Oregon, USA). Samples were viewed under low vacuum conditions using 10 $\mathrm{kV}$, spot size 2, 0.7 Torr using a GSE detector.

\section{Energy dispersive X-ray analysis (EDXA)}

Standard methods, similar to the SEM procedure, were used for preparation. Specimens were examined and positioned with the above SEM instrument, which was equipped with a Phoenix energy-dispersive $\mathrm{x}$-ray analyzer (FEI). X-ray spot analysis and live scan analysis were performed at $16 \mathrm{kV}$ with a spot size of 5 and results were recorded on charts and stored with digital imaging software attached to a computer. The TEAM (Texture and Elemental Analytical Microscopy), a modification of the EDXA system (Energy Dispersive X-ray analysis), software system (FEI) was used. The data included the weight and atom percentages of the detected elements following correction factors.

\section{Histopathological observations}

Biopsied host tissues with attached monogeneans previously fixed with $10 \%$ formalin were processed by the standard methods for paraffin-blocked specimens [12,13]. The paraffinblocked tissue was sectioned at 4-5 microns, placed on glass slides and stained with hematoxylin and eosin (H\&E). Additional sections were stained with Mallory's trichrome to study the pathological responses to the parasite [14]. H\&E as a standard stain for tissue whereas Mallory's trichrome to differentiate granular tissue typical of parasite invasion. The prepared sections were viewed with a LSM laser (Carl Zeiss, Thornwood, New York, USA) equipped compound microscope and representative pictures were taken at varying magnifications with a digital camera. The histopathological sections were selected from a much larger collection of sections on 63 glass slides in RAH's collection. The following abbreviations were used in histopathological studies: CF-collagenous fibers, Ep-stratified epithelium, H-hemorrhaging, N-necrosis, S-sucker.

\section{RESULTS}

\section{Infection status with O. hippopotami}

A total 5 out of 6 examined hippopotami (83.3\%) were infected with $O$. hippopotami, intensity range 4-97 (36) (Table 1). Commonly both eyes of hippopotami were infected (Table 1). Parasites had a firm grip on host tissues and they were never found detached. Most of these parasites were found on the 
nictitating membrane of eyes, and seldom on the side of the eye globe (Fig. 1). Different attachment sites were seen on the host's eyes (Fig. 1C, D) with parasites forming clusters on several cases.

Table 1. Collections of Oculotrema hippopotami from adults Hippopotamus amphibius in Mpumalanga Province, South Africa

\begin{tabular}{|c|c|c|c|c|c|}
\hline \multirow{2}{*}{ Host No. } & \multirow{2}{*}{ Coordinates } & \multirow{2}{*}{ Gender of host } & \multicolumn{3}{|c|}{ No. of monogeneans recovered in } \\
\hline & & & Right eye & Left eye & Total \\
\hline 1 & $24^{\circ} 48^{\prime} \mathrm{S} 31^{\circ} 30^{\prime} \mathrm{E}$ & $\mathrm{F}$ & 9 adults & 9 adults & 18 \\
\hline 2 & $24^{\circ} 57^{\prime} \mathrm{S} 31^{\circ} 28^{\prime} \mathrm{E}$ & M & 2 adults & 2 sub-adults & 4 \\
\hline 3 & $24^{\circ} 35^{\prime} \mathrm{S} 31^{\circ} 11^{\prime} \mathrm{E}$ & $\mathrm{F}$ & no parasites & no parasites & - \\
\hline 4 & $24^{\circ} 06^{\prime} S 31^{\circ} 12^{\prime} \mathrm{E}$ & M & 54 adults & 43 adults & 97 \\
\hline 5 & $24^{\circ} 06^{\prime} S 31^{\circ} 12^{\prime} \mathrm{E}$ & M & 14 adults, 3 sub-adults & 10 adults & 27 \\
\hline 6 & $24^{\circ} 06^{\prime} \mathrm{S} 31^{\circ} 12^{\prime} \mathrm{E}$ & M & 12 adults, 1 sub-adult & 20 adults, 1 sub-adult & 34 \\
\hline
\end{tabular}

F, female; M, male.
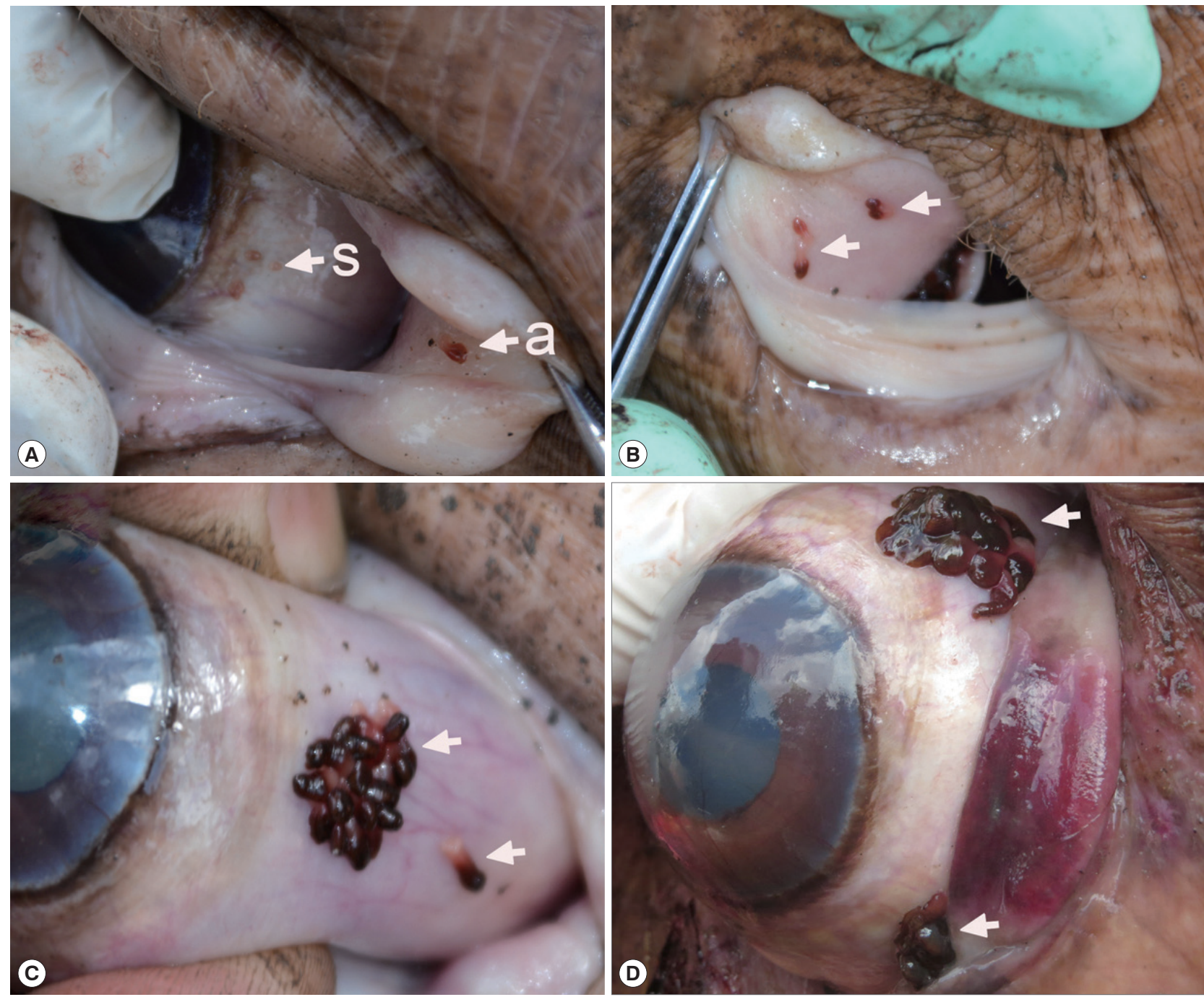

Fig. 1. Position of Oculotrema hippopotami on the host eye. (A) O. hippopotami sub-adults (s) on a globe of the eye and an adult (a) on a nictitating membrane. (B) 4 adults (arrows) on a nictitating membrane of the eye of hippopotamus. (C) Cluster of adults of $O$. hippopotami and 1 adult just been detached off the host tissue (arrows). (D) The rare case of the presence of 2 clusters of O. hippopotami at the same eye globe. 
A

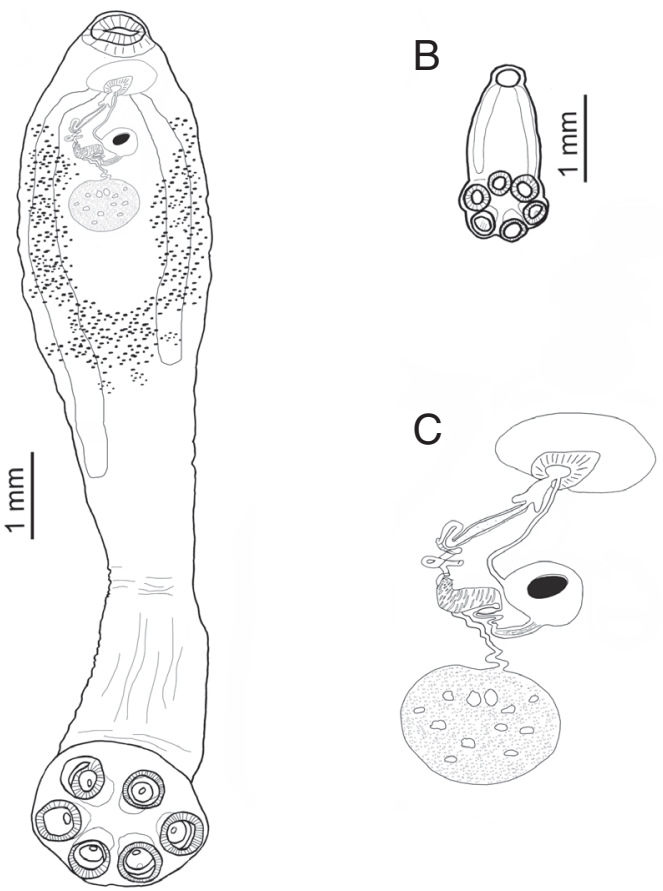

Fig. 2. Comparative sizes of an adult and sub-adult form of Oculotrema hippopotami. (A) Adult form of O. hippopotami, ventral view. (B) Sub-adult form of O. hippopotami, dorsal view. (C) Reproductive system of an adult form of $O$. hippopotami.

\section{Morphological characteristics of O. hippopotami}

Distinguishing features between adults and sub-adults of $O$. hippopotami Monogeneans of 2 age groups, adults and subadults were recorded from the hosts. Two hosts were infected with adults only, while 1 host was uninfected (Table 1). Adults were easily distinguished from sub-adults with the naked eye: they were large, with a cherry-red anterior $2 / 3$ of the body, collected in clusters of at least 5 or more individuals (Figs. 1, 2). Sub-adults were found separately from the cluster of adults and were noticeably smaller (Fig. 2), with an underdeveloped reproductive system. They were colorless, or white-yellowish to slightly pinkish (Fig. 1A). X-ray scans also showed major differences between the sub-adult and adult (see below). The most distinctive feature between the 2 age groups was the body size. Adults of $O$. hippopotami were on average 4.6 times larger than sub-adults (Fig. 2A, B; Table 2). Measurements of adults and sub-adults and comparisons with the original description and latest report [4] provided in Table 2. Sub-adults found in the present study varied in size and degree of development. The presence of a mixture of different generations on the same host for Oculotrema (in contrast to Polystoma Zeder, 1800) was a novel observation in the present study.

Table 2. Measurements of adults and sub-adults of Oculotrema hippopotami (in mm)

\begin{tabular}{|c|c|c|c|c|c|c|}
\hline \multirow{2}{*}{ Structure } & \multirow{2}{*}{$\begin{array}{l}\text { Stunkard, } \\
1924\end{array}$} & \multirow{2}{*}{$\begin{array}{c}\text { Adults } \\
\text { (Du Preez et al., } 2004 \text { [4]) }\end{array}$} & \multicolumn{2}{|c|}{ Adults (Present study) } & \multicolumn{2}{|c|}{ Sub-adults (Present study) } \\
\hline & & & Mean (Range) & $\mathrm{N}$ & Mean (Range) & $\mathrm{N}$ \\
\hline Body length & $3.0-5.2^{\mathrm{a}}$ & $17.28(12.31-32.51)$ & $9.17(4.00-16.25)$ & 12 & $2.60(1.20-4.30)$ & 8 \\
\hline Greatest width & $1.1-2.2$ & $2.60(20.5-3.10)$ & $2.19(1.88-2.75)$ & 12 & $1.01(0.56-1.35)$ & 8 \\
\hline Haptor length & 1.7 & $2.05(1.59-2.56)$ & $1.41(0.63-1.88)$ & 12 & $0.80(0.56-1.18)$ & 8 \\
\hline Haptor width & $1.0-1.35$ & $2.27(1.90-2.97)$ & $1.77(1.18-2.75)$ & 12 & $1.13(0.70-1.30)$ & 8 \\
\hline Body/haptor length ratio & $1.8-3.0^{b}$ & $8.4^{b}$ & $6.5(6.4-8.67)$ & 12 & $3.25(2.4-3.66)$ & 8 \\
\hline Haptoral sucker diameter & 0.5 & $0.51(0.41-0.64)$ & $0.51(0.33-0.75)$ & 12 & $0.375(0.198-0.520)$ & 8 \\
\hline Haptor width/haptor sucker ratio & $2-2.7^{b}$ & $4.5^{\mathrm{b}}$ & $3.45(3.62-3.67)$ & 12 & $3.01(2.50-3.52)$ & 8 \\
\hline Oral sucker diameter & 0.36 & $0.82(0.69-0.92)$ & $0.75(0.47-1.10)$ & 12 & $0.23(0.14-0.31)$ & 8 \\
\hline Pharynx length & $n / a^{c}$ & $0.49(0.41-0.56)$ & $0.46(0.31-0.60)$ & 12 & $0.23(0.14-0.31)$ & 6 \\
\hline Pharynx width & $\mathrm{n} / \mathrm{a}$ & $0.70(0.62-0.82)$ & $0.64(0.44-0.88)$ & 12 & $0.31(0.15-0.42)$ & 6 \\
\hline Uterus length & $\mathrm{n} / \mathrm{a}$ & $1.05(0.64-1.54)$ & $0.50(0.30-1.00)$ & 12 & $0.19(0.18-0.21)$ & 2 \\
\hline Uterus width & $\mathrm{n} / \mathrm{a}$ & $1.07(0.54-1.67)$ & $0.58(0.35-1.35)$ & 12 & $0.19(0.17-0.21)$ & 2 \\
\hline Ovary length & 0.3-0.5 & $0.54(0.28-0.87)$ & $0.28(0.12-0.45)$ & 12 & $0.15(1.14-0.16)$ & 5 \\
\hline Ovary width & $0.14-0.2$ & $0.20(0.14-0.26)$ & $0.14(0.09-0.18)$ & 12 & $0.21(0.09-0.33)$ & 5 \\
\hline Testis length & $0.2-0.37$ & $0.90(0.69-1.13)$ & $0.58(0.42-0.95)$ & 12 & $0.23(0.12-0.36)$ & 5 \\
\hline Testis width & $0.7-0.9$ & $0.94(0.59-1.21)$ & $0.82(0.60-1.13)$ & 12 & $0.28(0.15-0.45)$ & 5 \\
\hline No. of intra-uterine eggs & 4-12 & $26(1-58)$ & $9(1-19)$ & 12 & $\mathrm{n} / \mathrm{a}$ & \\
\hline Egg length & $0.23-0.27$ & $0.23(0.21-0.24)$ & $0.24(0.20-0.30)$ & 12 & $n / a$ & \\
\hline Egg diameter & $0.12-0.14$ & $0.14(0.13-0.14)$ & $0.11(0.07-0.14)$ & 12 & $\mathrm{n} / \mathrm{a}$ & \\
\hline Marginal hooklet length & $\mathrm{n} / \mathrm{a}$ & $0.0149(0.0147-0.0152)$ & $\mathrm{n} / \mathrm{a}$ & & $\mathrm{n} / \mathrm{a}$ & \\
\hline $\begin{array}{l}\text { Thick-walled muscular portion } \\
\text { of vas deferens length }\end{array}$ & $\mathrm{n} / \mathrm{a}$ & $\mathrm{n} / \mathrm{a}$ & $0.45(0.26-0.62)$ & 3 & $0.16(0.15-0.17)$ & 5 \\
\hline Cirrus diameter & 0.05 & $\mathrm{n} / \mathrm{a}$ & $0.11(0.10-0.13)$ & 3 & $0.08(0.05-0.10)$ & 6 \\
\hline
\end{tabular}

aData provided at the original description (Stunkard, 1924 [5]) from highly contracted adults.

bOur calculations, based on published data.

'Not available. 
Morphological features of an adult O. hippopotami (Fig. 2A and Fig. 3A)

Measurements listed in Table 2. The average haptor width/ haptor sucker ratio was 3.2 (Table 2) and the average body/ haptor length ratio 6.5 . The musculature of the oral sucker in the adult well developed, with few tissue layers (Fig. 3C). Ven- tral part of the body flattened, possibly due to the life-long mode of attachment of the worms. Likewise, the oral sucker opening also oriented in the same plane (Fig. 3B). The genital system is shown on Fig. 2C. The muscular cirrus with ejaculated sperms are shown in Figs. 3C, D. Arrows on Figs. 3C, E show the position of a genital papilla present in adults of $O$. hippo-
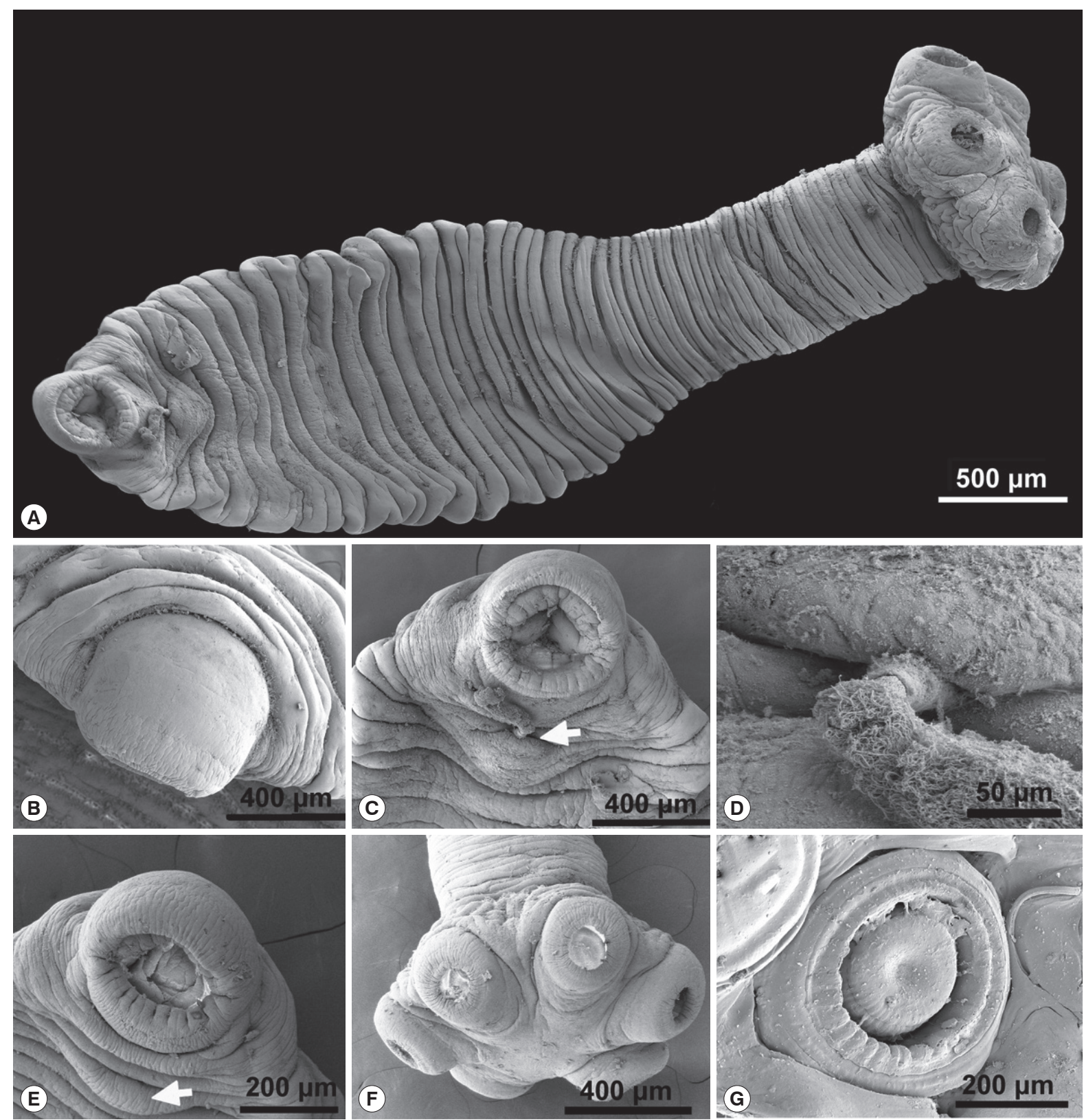

Fig. 3. SEM of adult Oculotrema hippopotami. (A) The whole body view of an adult O. hippopotami, cuticle partly contracted. (B) View from the top of the mouth end of the worm. (C) Genital papilla (arrow) and muscular copulatory organ of O. hippopotami, with ejaculated sperms. (D) Higher magnification of muscular copulatory organ of $O$. hippopotami, with ejaculated sperms. (E) The position of the genital papilla at adult specimens of O. hippopotami. (F) Haptor of an adult O. hippopotami with 6 suckers. (G) Lateral view of one of the 6 suckers of an adult $O$. hippopotami. 
potami. Figs. 3F, G show the haptor and one of 6 well-developed suckers of an adult, designed for a very firm long-term attachment to the host tissue. The haptor width/haptor sucker ratio measured for the current study was 3.45 (3.62-3.67) in comparison with up to 4.5 of Du Preez et al. [4]. Tegument consists of plates elastically connected to each other and strands between plates. The attachment of sclerotized structures also differs structurally (see X-rays analysis part of the study). The external edges of suckers in the sub-adult form may be folded or corrugated (Figs. 4A, F, G).
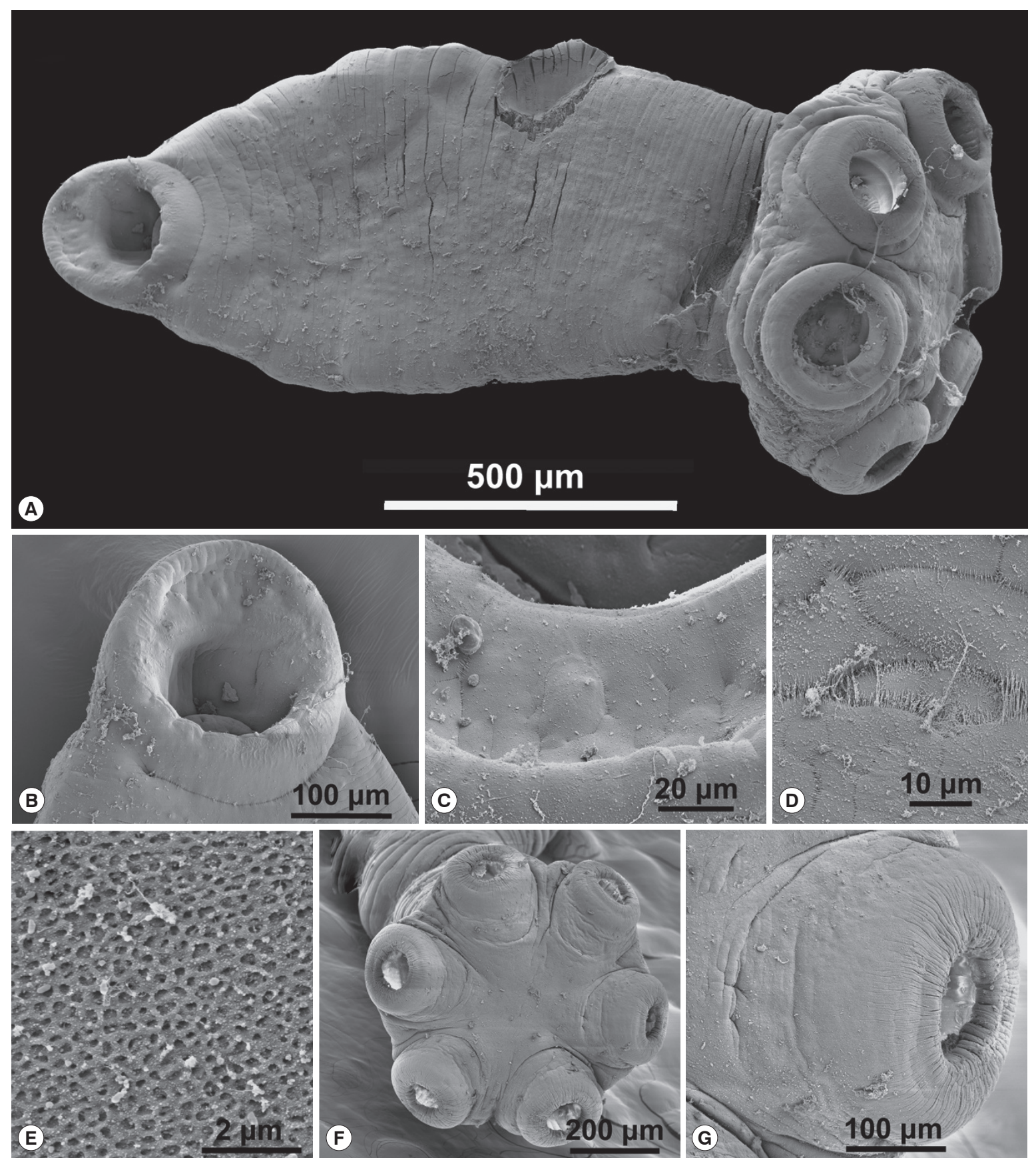

Fig. 4. SEM of sub-adult Oculotrema hippopotami. (A) The whole body view of a sub-adult O. hippopotami. (B) Oral sucker of a subadult O. hippopotami. (C) Magnified oral sucker of a sub-adult O. hippopotami. (D) Tegument plates of sub-adult O. hippopotami. (E) Honeycomb structure of tegument of sub-adult of $O$. hippopotami. (F) En face view of the 6 muscular suckers of haptor of sub-adult of O. hippopotami. (G) Higher magnification of haptor sucker of sub-adult of O. hippopotami. 
Morphological features of a sub-adult O. hippopotami (Fig. 2B and Fig. 4A)

Measurements listed in Table 2. The average haptor width/ haptor sucker ratio was 2.9. The average body/haptor length ratio in sub-adults was 3.25. The musculature of the oral sucker undeveloped (Fig. 4B, C for a close view). Ventral part of the body flattened. Oral sucker opening oriented at an angle to the plane of the ventral part of the body (Fig. 4B). Genital papilla not seen. Suckers not as well developed as in the adult forms. Haptor width/haptor sucker ratio was 3.01 (2.50-3.52). Repro- ductive organs of the smallest sub-adults were not developed. The tegument consists of plates elastically connected to each other (Fig. 4D) with strands between plates. The tegument had a honeycomb-structure (Fig. 4E). En face view of the 6 muscular suckers of $O$. hippopotami depicted in Fig. 4F. The position of suckers and their orientation was similar to the adult form, but the relative ratio of the sucker to the haptor and haptor to body differed (Table 2). Haptor suckers were smaller and less developed in comparison with adults (Fig. 4G).
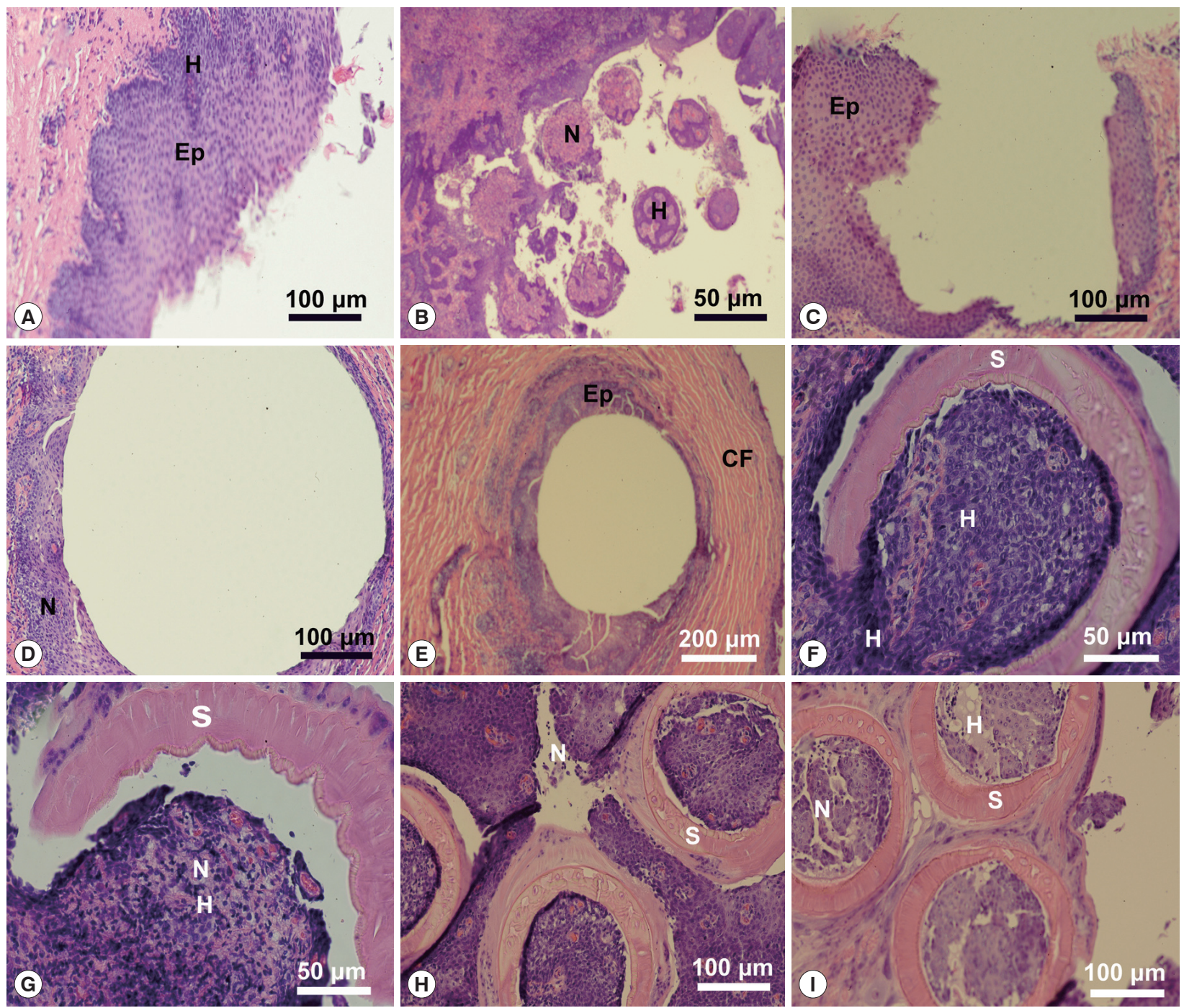

Fig. 5. Histopathology of Oculotrema hippopotami. (A) Lateral orbit of the eye socket of a hippopotamus. Surface of the eye of the host. (B) Section of an infected hippopotamus eye displaying the 6 circles of host tissue pulled away from the surface of the eye. (C) Area of the host eyes where the monogenean O. hippopotami had been attached. (D) Surface of the host eye where O. hippopotami had been attached. (E) Area of the host eye where the worm was attached. (F) The result of a parasite sucker attaching to the host epithelium. (G) A single worm sucker surrounding necrotic host tissue causing extensive hemorrhaging. (H) Result of 3 parasite suckers attached to the surface of the eye. (I) Similar to figure $\mathrm{H}$ showing 3 of the 6 parasite suckers showing disruption of eye tissue of the host. 
Histopathologic findings on the effect of $O$. hippopotami infections in the eyes of hippopotamus

A lateral orbit of the eye socket of a hippopotamus was shown in Fig. 5A. This figure shows the surface of the eye of the host; a stratified epithelial lining with a connective tissue base below the basement membrane. There were extensive hemorrhaging (disruption of capillary vessels) and pooled blood cells as well as necrotic tissue in the area where parasites attached (Fig. 5B), which displayed a section of an infected hippopotamus eye pulled away from the surface of the eye. It displayed the 6 marks of host tissue where suckers attached. An area of the host eyes where specimens of O. hippopotami had been attached shown in Fig. 5C. Note the difference between normal host epithelium and epithelium in the invaded

Table 3. Energy dispersive X-ray analysis for adults and sub-adults of Oculotrema hippopotami

\begin{tabular}{|c|c|c|c|c|c|c|c|}
\hline \multirow{2}{*}{ Elementa $^{\mathrm{a}}$} & & \multicolumn{2}{|c|}{ Body } & \multicolumn{2}{|c|}{ Mouth } & \multicolumn{2}{|c|}{ Sucker } \\
\hline & & Adult & Sub-Adult & Adult & Sub-Adult & Adult & Sub-Adult \\
\hline Carbon & $\mathrm{C}$ & $18.7^{b}(20.2)^{c}$ & 20.37 (18.83) & 14.07 (15.59) & $16.69(15.31)$ & $16.97(17.47)$ & $19.51(15.50)$ \\
\hline Nitrogen & $\mathrm{N}$ & 35.18 (35.44) & 34.97 (39.00) & 36.88 (34.03) & 36.56 (36.66) & 33.19 (34.75) & $33.24(29.21)$ \\
\hline Oxygen & $\mathrm{O}$ & 29.19 (33.02) & 34.68 (31.83) & $35.53(35.00)$ & 35.47 (35.83) & 30.72 (33.63) & 33.37 (25.94) \\
\hline Magnesium & $\mathrm{Mg}$ & $0.03(0.29)$ & $0.08(0.25)$ & $0.05(0.04)$ & $0.03(0.34)$ & $0.30(0.14)$ & $0.02(0.33)$ \\
\hline Phosphorus & $\mathrm{P}$ & $0.34(0.56)$ & $0.42(0.73)$ & $0.04(0.67)$ & $0.00(0.19)$ & $0.65(0.20)$ & $0.16(0.78)$ \\
\hline Sulfur & S & $0.73(0.96)$ & $0.54(0.03)$ & $0.72(0.77)$ & $0.25(0.35)$ & $1.05(0.68)$ & $0.74(1.35)$ \\
\hline Calcium & $\mathrm{Ca}$ & $0.72(0.49)$ & $0.30(0.18)$ & $1.43(0.94)$ & $0.34(0.51)$ & $1.57(0.77)$ & $0.35(0.41)$ \\
\hline
\end{tabular}

aTwo scans for each area on different specimens. Scans of the body, mouth and suckers for 2 life stages. The coating and processing chemicals (Au, $\mathrm{Pd}$ and Os) are not included.

${ }^{b}$ Weight, $\%$.

Atom, \%.
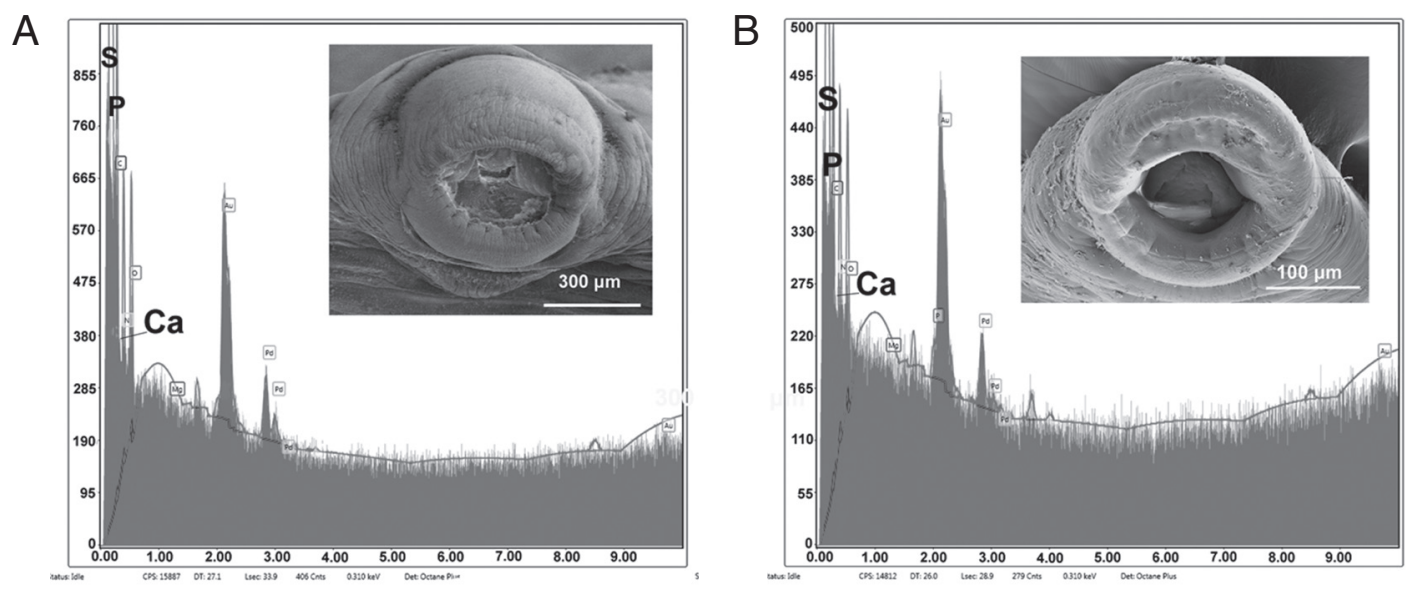

\begin{tabular}{lcccc}
\hline Element & $\begin{array}{c}\text { Weight } \\
\%\end{array}$ & $\begin{array}{c}\text { Atomic } \\
\%\end{array}$ & $\begin{array}{c}\text { Error } \\
\%\end{array}$ & $\begin{array}{c}\text { Net } \\
\text { Int. }\end{array}$ \\
\hline $\mathrm{C}$ & 19.49 & 29.29 & 8.23 & 197.91 \\
$\mathrm{~N}$ & 32.33 & 41.66 & 12.56 & 140.91 \\
$\mathrm{O}$ & 22.65 & 25.56 & 11.81 & 149.51 \\
$\mathrm{Mg}$ & 0.03 & 0.02 & 78.19 & 0.88 \\
$\mathrm{P}$ & 0.52 & 0.3 & 58.88 & 16.59 \\
$\mathrm{Au}$ & 18.11 & 1.66 & 9.94 & 237.49 \\
$\mathrm{~S}$ & 0.54 & 0.3 & 63.5 & 16.07 \\
$\mathrm{Pd}$ & 5.89 & 1 & 22.9 & 73.43 \\
$\mathrm{Ca}$ & 0.45 & 0.2 & 59.58 & 7.73 \\
\hline
\end{tabular}

\begin{tabular}{lcccc}
\hline Element & $\begin{array}{c}\text { Weight } \\
\%\end{array}$ & $\begin{array}{c}\text { Atomic } \\
\%\end{array}$ & $\begin{array}{c}\text { Error } \\
\%\end{array}$ & $\begin{array}{c}\text { Net } \\
\text { Int. }\end{array}$ \\
\hline $\mathrm{C}$ & 21.02 & 32.77 & 8.52 & 351.34 \\
$\mathrm{~N}$ & 25.99 & 34.76 & 13.49 & 178.73 \\
$\mathrm{O}$ & 23.7 & 27.75 & 11.31 & 288.77 \\
$\mathrm{Mg}$ & 0.18 & 0.14 & 64.07 & 9.64 \\
$\mathrm{P}$ & 0.98 & 0.59 & 20.45 & 54.85 \\
$\mathrm{Au}$ & 19.64 & 1.87 & 7.96 & 449.24 \\
$\mathrm{~S}$ & 0.79 & 0.46 & 35 & 40.71 \\
$\mathrm{Pd}$ & 6.63 & 1.17 & 18.71 & 143.3 \\
$\mathrm{Ca}$ & 1.07 & 0.5 & 45.82 & 32.31 \\
\hline
\end{tabular}

Fig. 6. EDXA data for the scan of the mouth sucker of Oculotrema hippopotami. (A) Adult specimen of O. hippopotami. (B) Sub-adult specimen of $O$. hippopotami. 
area (bottom left). The eye surface of the host has been altered as a result of the firm grip of parasites. Note tissue necrosis and hemorrhaging on the edges of the marking (Fig. 5D). See also Fig. 5E, showing host epithelial eye cells surrounding the point of attachment. Note the extensive encapsulation with collagenous fibers, in an attempt of the host to "wall-off" the parasite. Fig. 5F displayed the effect of a parasite sucker attaching to the host epithelium. Note the extensive tissue necrosis in the center of the attachment area of the sucker. Also note extensive necrosis caused the sucker and hemorrhaging of host tissue (Fig. $5 \mathrm{G})$. The effect of parasite suckers' attachment to the surface of the eye and the resulting necrotic tissue inside the sucker depicted in Fig. 5H. Note small capillaries scattered throughout the eye epithelium with red blood cells in the vessels. Compare this to Fig. 5I, which showed 3 of the 6 O. hippopotami suckers with a disruption of eye tissue and hemorrhaging with resulting cell necrosis. Note the corrugated nature of the sucker with specialized collagenous fibers. Compare to Fig. 5G with a single intact worm sucker surrounding host epithelial cells.

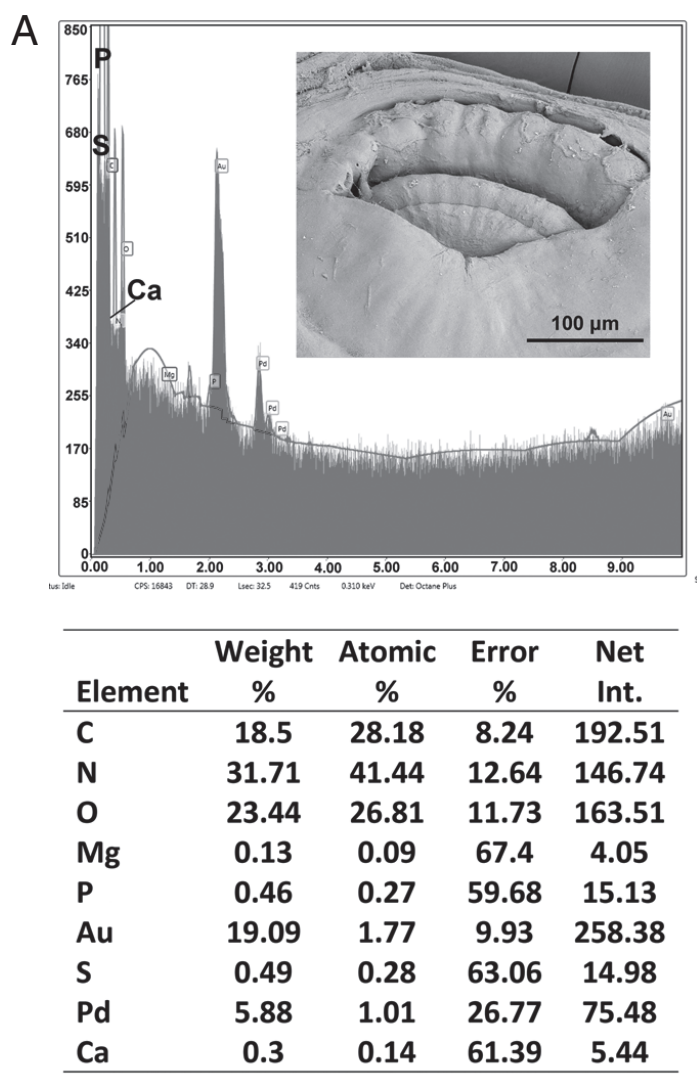

EDXA findings on the adult and sub-adult forms of $O$. hippopotami

Table 3 and Figs. 6, 7 contained the data for the X-ray scans of the adult and sub-adult worms. Three areas were scanned, i.e., body, mouth and sucker. Duplicate scans were done on different specimens for a qualitative evaluation to understand changes in the chemistry of the organism during its lifespan. The processing and coating chemicals $(\mathrm{Au}, \mathrm{Pd}$ and $\mathrm{Os})$ were omitted from the table. Note the definite lack of hardening ions $(\mathrm{Ca}, \mathrm{S}, \mathrm{P})$ in the scanned areas of the sub-adults. The common chemical ions ( $\mathrm{C}, \mathrm{N}$ and $\mathrm{O})$ in living protoplasm were consistent for both life stages.

\section{DISCUSSION}

Because of severe drought in August and September 2016 in northeastern South Africa and declining overall condition of hippopotami, a decision was made to control compromised animals from the Kruger National Park Associated Private Na-

B

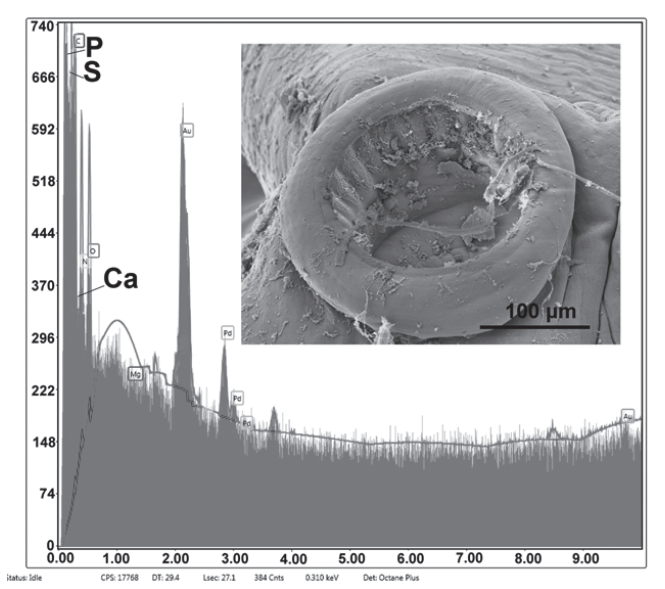

\begin{tabular}{lcccc}
\hline Element & $\begin{array}{c}\text { Weight } \\
\%\end{array}$ & $\begin{array}{c}\text { Atomic } \\
\%\end{array}$ & $\begin{array}{c}\text { Error } \\
\%\end{array}$ & $\begin{array}{c}\text { Net } \\
\text { Int. }\end{array}$ \\
\hline $\mathrm{C}$ & 21.56 & 32.28 & 8.21 & 287.41 \\
$\mathrm{~N}$ & 31.61 & 40.59 & 13.09 & 162.53 \\
$\mathrm{O}$ & 20.86 & 23.45 & 11.92 & 171.17 \\
$\mathrm{Mg}$ & 0.02 & 0.01 & 86.61 & 0.75 \\
$\mathrm{P}$ & 0.76 & 0.44 & 40.72 & 30.89 \\
$\mathrm{Au}$ & 18.31 & 1.67 & 10.85 & 306.15 \\
$\mathrm{~S}$ & 0 & 0 & 99.99 & 0.11 \\
$\mathrm{Pd}$ & 5.49 & 0.93 & 27.36 & 87.21 \\
$\mathrm{Ca}$ & 1.4 & 0.63 & 50.56 & 30.94 \\
\hline
\end{tabular}

Fig. 7. EDXA data for the scan of haptor sucker of Oculotrema hippopotami. (A) Adult specimen of O. hippopotami. (B) Sub-adult specimen of $O$. hippopotami. 
ture Reserves (APNR).

The present infection levels of $O$. hippopotami compare to that reported in the previous studies, and are very high and unique in Monogenea under natural conditions compared to almost all other representatives of Monogenea in general [15], and particularly Polystomatidae [16]. Five of 6 examined animals from the current study were infected. Thurston \& Laws reported a prevalence of $76 \%$ on a large sample size (960 of 1,263 hippopotami were positive for O. hippopotami) [1]. Du Preez et al. [4] reported a prevalence of $90 \%$. Several factors probably contribute to this phenomenon. Life in clusters ensures fertilization, and, consequently, the release of eggs into the water. A pronounced care for the offspring, the constant contact of the mother with the calf, and the presence of adult individuals in the proximity to the standing water ensures infection. The only serious obstacle is the mechanical influence on the worms of the eyelid during blinking, which they successfully overcome by developing a unique sclerotized suction attachment system. The degree of attachment to the tissues of the host is so strong that in a number of cases, it was practically impossible to tear off the monogeneans from the eye tissue. High levels of infection together with absence of obvious pathogenicity to the host indicate an extremely successful adaptation of this parasite to the host. The effect of the infection of this monogenean on the host does not appear to have an influence on visual acuity, since no studies indicated the presence of the $O$. hippopotami specimens in the anterior part of the eye or cornea.

New morphological features were revealed in the present study, such as flattened dorsal side of the body provided for the first time with SEM micrographs; the presence of genital papillae observed only in adults. In addition, differences were shown in the orientation of oral suckers between adults and sub-adults. The new information on sperm ejaculatory structures of O. hippopotami was shown with SEM micrographs. New metrical and graphical information obtained for adults and sub-adults were compared with previous studies. Finally, the metrical data on the distal part of the vas deferens is reported for the first time.

Halton and Jennings stated that specimens of $O$. hippopotami feed on epithelial cells and mucous [17]. Fig. 3B shows an adaptation of the whole body shape to this mode of nutrition flattened ventral side of the body contrasting with arched dorsal side. Earlier, Moeng et al. [18] reported that the oral sucker is designed for long-term positioning of the worm, clamped between the host's eyeball and eyelid. It was reported that the oral sucker morphology reflects the mode of feeding. The subterminal flat mouth of $O$. hippopotami was considered to scoop up the mucous and epithelial cells [18]. The musculature of oral sucker of adults is more developed than in sub-adults; compare Fig. 3C and Fig. 4B. The size of the worm suggests that increased food consumption causes greater development of the musculature of the oral sucker. Tegument structure revealed in the present study has a typical polystomatid honeycomb-structure (Fig. 4E) [19].

According to Tinsley [6], Du Preez et al. [4] and our observations, specimens of $O$. hippopotami do not possess a vagina, however Theunissen, mentioned its presence and marked it on a photograph (Figs. 2, 4, 7 pp 125) [9]. The cirrus of O. hippopotami has no armament [6] and because of this unarmed cirrus, hypodermal insemination that has been reported in other monogenean groups does not appear to be the case for O. hippopotami [4] and the process of insemination for this species remains unknown. Du Preez et al. [4] proposed that in O. hippopotami the sperm is introduced via the muscular cirrus directly in the genital atrium. Using SEM in the present study (Fig. 3C, D) we could show the muscular cirrus and ejaculated sperms; ejaculation possibly was triggered due the thermal or chemical effects during fixation of living worms in ethanol. Similar to the event observed in other groups of monogeneans (Diplozoidae), where placing living or recently dead monogeneans in a drop of glycerin-gelatin on a slide, triggers the ejection of the contents of the digestive tract as observed with a stereomicroscope (Rubtsova, unpublished data). The genital pore is surrounded by prominent muscular papilla (Fig. 3C, E), noted in all adult specimens, that may possibly play an important role in the process of insemination.

All infected hosts of the present study were infected with either adult worms, or a combination of adults and sub-adults. Our observations (see Fig. 1A), as well as observations of Du Preez et al. [4] (see Fig. 1B of the latter authors), demonstrate that the same individual hippopotamus can be infected by different generations of monogeneans during its lifespan. Moeng observed the same tendency [20]. Therefore, the assumption can be made that the presence of a mixture of different generations of $O$. hippopotami is a common occurrence in the eyes of hippopotamus as was noted during the current study in 3 of 6 studied hosts. This feature is more advantageous for the survival of the parasites. For representatives of Polystoma genus, on the contrast, it is typical to see only one age group present in 
the urinary bladder of one anuran amphibian host [19,21] .

It was previously noted by Du Preez et al. [4], as well as seen during the present study, that $O$. hippopotami spend their lifespan in clusters or groups in certain part of the hippo's eye. Sub-adults found on the same eye together with adults somehow settle away from the adult clusters. This may be related to the necessity of mutual fertilization of individuals of one cluster. Adults appear to stay together in clusters during their lifetime. Sub-adults usually found separately from the cluster of adults and may begin a new colony and not compete for the resources with parental specimens (Fig. 1A(s)), also see Fig. 1B in Du Preez et al. [4].

The size differences were the most reliable characteristics for differentiation of adult and sub-adult forms of polystomatid monogeneans [21]. Measurements of body size of sub-adults in the present study (Table 2) are comparable to those of adults described by Stunkard [5]. The presence of eggs and the level of development of the reproductive system (dimensions of uterus, ovary and testes) of Stunkard's [5] specimens correspond to the dimensions mentioned by Du Preez et al. [4] and our data for adults. Differences in body size may be due to extremely contraction of the worms as mentioned in the original description [5].

In our study, the average body length of an adult was 3.5 times larger than that of sub-adults. Note that the length of the body for $O$. hippopotami is very variable due to its ability to contract. As was noted in the present study, the tegument, that has a honeycomb-structure, consists of plates elastically connected to each other (Fig. 4D) with strands between plates. This structure allows the body of $O$. hippopotami to stretch freely in length and shrink almost into a sphere as observed during this study. Considering the maximum measurement of body length from Du Preez et al. [4] for an adult being 32.51 $\mathrm{mm}$ and minimal length of sub-adults in our study is $1.2 \mathrm{~mm}$, this ratio could reach 27 .

The relative size of the suckers to the size of the haptor varies (3.2 in adults to 2.9 in sub-adults), but not as significantly as the ratio of the size of the haptor to the length of the body (6.8 in adults to 3.7 in sub-adults).

Most of the measurements of adults are within the variability range specified in previous publications, except for a notable difference in body length and width in the original description that is noticeably smaller than those described in Du Preez et al. [4] and the present study. We also report herein the length of a thick-walled muscular portion of the vas deferens and the diam- eter of the cirrus for both adults and sub-adults for the first time.

Du Preez et al. [4] mentioned the prominent bud-shaped attachment marks left after the removal of the parasite. The present study indicates a convexity of host tissue is grabbed inside the sucker. Pathological changes in the host tissues included necrosis and hemorrhage at the sites of attachment of the parasite. See Fig. 5 for pathological changes in the host tissue at attachment sites that are due to the mode of the attachment of $O$. hippopotami. The suction is aided by skeletal musculature and reinforced with an internal skeleton of the suckers [6]. During its evolution, O. hippopotami lost its hamuli, due to the delicate habitat, where irritation of host tissue could be disadvantageous [6]. It is quite possible that such kind of influence does not have a pronounced negative effect on the functions of the host as a whole, but mostly by putting a burden on the tissue immunity. Most likely the presence of O. hippopotami in the eye (both on the side of the globe or on nictitating membrane (but never on cornea) does not affect the visual acuity of the hippopotamus. Similar changes in attachment points are also known for other groups of parasites, for example, acanthocephalans [23].

Such pathological changes, i.e. necrosis and hemorrhage found at the host tissues, cause a slight deterioration in the quality of life of the host (parasite, obviously never is an obstacle to the eyesight acuity of the host). Thus, this parasitehost system is an example of an almost ideal mutual adaptation, and O. hippopotami can be considered one of the most successful monogeneans.

Structural analysis of different body parts of $O$. hippopotami in both age groups are also reported for the first time and shows qualitative differences in the presence of hardening ions (S, P, Ca) in attachment structures (oral and haptor suckers) that increases with the age of the worm. EDXA has been used to track the change in chemical ions for areas of a parasite that become hardened with age (forming chemical bonds such as sulfide bonds for amino acids, apatite formation). This allows the parasite to harden certain areas of the body for attachment to the host. In the case of Oculotrema, this tendency for suckers of haptor and in oral sucker was observed. The skeletal complex of the suckers of Oculotrema is incredibly complex, consisting of few layers of 3 annular zones [9], which provide a strong retention of the parasite, which is impeded by the constant movement of the eyelid throughout the parasite's lifetime. Chemical compounds of these structures change with the age of the parasite, while its body grows 3-5 times bigger 
with a general tendency of accumulating of hardening ions $(\mathrm{Ca}, \mathrm{S}, \mathrm{P})$ in the areas of the attachment structures. This tendency is very weak in body wall structure, where accumulation of hardening ions changes insignificantly with age (Table 3). The same tendencies were shown for the hooks of acanthocephalans [24-26].

\section{AKNOWLEDGMENTS}

NYR was supported by an institutional grant from the Institute of Parasitic Diseases, Scottsdale, Arizona. We are grateful to Michael Standing who provided assistance with the SEM and EDXA processing in the BYU Electronic lab. Our gratitude goes to the Histology lab personnel (Utah Valley Regional Medical Centre), where histological slides were prepared. We thank Mpumalanga Tourism and Parks Agency (MTPA) and the management of the Private Game Reserves for providing carcasses of hippos for research and allowing us to investigate health and disease, including parasitic infections, in the population. We also thank people who helped during the fieldwork, especially Pieter Olivier, Kris Bal, Hendrik Hattingh, Jean Roux, Katlego D. Kunutu, Makubu P. Mokgawa and Nokukhanya Makuwa. This work is based on the research supported by the South African Research Chairs Initiative of the Department of Science and Technology and National Research Foundation (NRF) of South Africa (Grant No 101054). Any opinion, finding and conclusion or recommendation expressed in this material is that of the author(s) and the NRF does not accept any liability in this regard.

\section{CONFLICT OF INTEREST}

We have no conflict of interests related to this work.

\section{REFERENCES}

1. Thurston JP, Laws RM. Oculotrema hippopotami (Trematoda: Monogenea) in Uganda. Nature 1965; 205: 1127.

2. Jooste R. A checklist of the helminth parasites of the larger domestic and wild mammals of Zimbabwe. Trans Zimbabwe Sci Assoc 1990; 64: 15-32.

3. McCully RW, van Niekerk JW, Kruger SP. Observation of the pathology of bilharsiasis and other parasitic infestations of Hippopotamus Linnaeus, 1758, from the Kruger National Park. Onderstepoort J Vet Res 1967; 34: 563-617.

4. Du Preez LH, Moeng IA. Additional morphological information on Oculotrema hippopotami Stunkard, 1924 (Monogenea: Polystomatidae) parasitic on the African hippopotamus. Afr Zool 2004; 39: 225-233.

5. Stunkard HW. A new trematode, Oculotrema hippopotami n.g., n.sp, from the eye of the hippopotamus. Parasitology 1924; 16: 436-440.

6. Tinsley RC. The oncomiracidium of Oculotrema hippopotami Stunkard, 1924 and relationships within the Polystomatidae (Monogenea). Syst Parasitol 2013; 84: 123-135.

7. Thurston JP. The larva of Oculotrema hippopotami (Monogenea: Polystomatidae). J Zool 1968; 154: 475-480.

8. Thurston JP. Haemoglobin in a Monogenean, Oculotrema hippopotami. Nature 1970; 228: 578-579.

9. Theunissen M. Morphology and functioning of attachment organs of the Polystomatidae (Monogenea) [master's thesis]. [Potchefstroom]: North-West University; 2014, pp 1-159.

10. Halajian A, Luus-Powell WJ, Roux F, Nakao M, Sasako M, Lavikainen A. Echinococcus felidis in hippopotamus, South Africa. Vet Parasitol 2017; 243: 24-28.

11. Lee RE. Scanning Electron Microscopy and X-ray Microanalysis. Englewood Cliff, USA. Prentice Hall. 1993, pp 1-458.

12. Bancroft JD, Gamble M. Theory and Practice of Histological Techniques. 5th ed. Edinburgh, UK. Churchill Livingston. 2001, pp 1-800.

13. Keinan JA. Histological and Histochemical Methods: Theory and Practice. Edinburgh, UK. Churchill Livingston. 2001, pp 1-520.

14. Galigher AE, Kozloff EN. Essentials of Practical Microtechnique. 2nd ed. Philadelphia, USA. Lee \& Febiger. 1971, pp 1-531.

15. Miroshnichenko AI. Monogeneans of freshwater fish of Crimea. In Scarlato OA ed, Studies of Monogeneans in the USSR. Leningrad, USSR. Zoological Institute of Academy of Sciences of USSR. 1977, pp 102-103 (in Russian).

16. Tinsley RC, Jackson JA. Host factors limiting monogenean infections: a case study. Int J Parasitol 2002; 32: 353-365.

17. Halton DW, Jennings JB. Observation on the nutrition of monogenetic trematodes. Biol Bull 1965; 129: 257-272.

18. Moeng IA, Du Preez LH. Oral sucker morphology of two polystomatids (Monogenea): one blood feeding and one mucous feeding. Microsc Soc South Africa 1997; 27: 116.

19. Rubtsova NYu, Heckmann RA. Morphological and structural differences of normal adult and sub-adult bladder forms of Polystoma integerrimum (Fröhlich, 1798) (Monogenea: Polystomatidae) from the common frog, Rana temporaria. Sci Parasitol 2017; 18: 38-53.

20. Moeng IA. Aspects of the morphology and life history of Oculotrema hippopotami (Polystomatidae: Monogenea) [master's thesis]. [Bloemfontein]: University of the Orange Free State Bloemfontein; 1999, pp 1-108.

21. Rubtsova NYu. Redescription and variability of Polystoma mazurmovici and P. skuratovitchi (Monogenea, Polystomatidae), with a key to Polystoma from anurans of Ukraine. Vestn Zool 2018; 52: 91-100. 
22. Roberts LS, Janovy J Jr. Foundations of Parasitology. 5th ed. Boston, USA. Wm. C. Brown Publishers. 1996, pp 281-296.

23. Amin OM, Heckmann RA, Bannai MA. Cavisoma magnum (Cavisomidae), a unique Pacific acanthocephalan redescribed from an unusual host, Mugil cephalus (Mugilidae), in the Arabian Gulf, with notes on histopathology and metal analysis. Parasite 2018; $25: 5$.

24. Amin OM, Heckmann RA, Mohammed O, Evans RP. Morphological and molecular descriptions of Moniliformis saudi sp. $\mathrm{n}$. (Acanthocephala: Moniliformidae) from the desert hedgehog,
Paraechinus aethiopicus (Ehrenberg) in Saudi Arabia, with a key to species and notes on histopathology. Folia Parasitol 2016; 63: 14. 25. Amin OM, Heckmann RA. Neoandracantha peruensis n. gen. n. sp. (Acanthocephala, Polymorphidae) described from cystacanths infecting the ghost crab Ocypode gaudichaudii on the Peruvian coast. Parasite 2017; 24: 40.

26. Amin OM, Heckmann RA. Rhadinorhynchus oligospinosus n. sp. (Acanthocephala, Rhadinorhynchidae) from mackerels in the Pacific Ocean off Peru and related rhadinorhynchids in the Pacific, with notes on metal analysis. Parasite 2017; 24: 19. 
